\title{
Irrelevant Behaviour, Information Processing and Arousal Homeostasis*
}

\author{
Juan D. DeLtus \\ Department of Psychology, University of Durham, Durham, England \\ and Department of Neurosciences, University of California, \\ San Diego, U.S.A.
}

\begin{abstract}
Summary. This paper expands a new hypothesis on the causal mechanisms underlying irrelevant behaviour. It begins with a critical summary of earlier theories which attempted to explain displacement activities, but failed to predict the consistency with which certain types of behaviour are shown in stressful situations by a variety of species. Behavioural and physiological studies suggest that these behaviour patterns are closely associated with the incipient activation of sleep. The functional significance of this link and some of the causal processes which may be responsible for it are discussed. Paradoxically, however, displacement activities occur when animals are in a state of high arousal. The concept of arousal is reconsidered in the light of information theory and assumed to be closely correlated with the information processing rate in the nervous system. The relationships between neural and autonomic arousal are considered in this context. It is argued that over-arousal may occur when information handling exceeds the limited channel capacity of the system, with a consequent loss of efficiency. It is pointed out that there are mechanisms capable of controlling the information influx into the brain, and it is hypothesized that they are tied up in a feedback mechanism which regulates arousal and which involves the activation of a de-arousal system, corresponding to the neurological sleep mechanism. Displacement activities are viewed as consequences of this regulatory activation of the sleep system. This hypothesis is then compared with existing theories of displacement and its relationship with them is discussed.
\end{abstract}

Zusammenfassung. Die Arbeit erweitert eine neue Hypothese über die kausalen Mechanismen, die dem Utbersprungverhalten zugrunde liegen. Sie beginnt mit einer kritischen Ubersicht der früher vorgeschlagenen Theorien und zeigt auf, daß diese nicht die Beständigkeit, mit der gewisse Verhaltensweisen von einer Anzahl von Tierarten in Stress-Situationen gezeigt werden, erklären. Verhaltens- und physiologische Studien deuten an, daß diese Verhaltensweisen in einem engen Zusammen-

* The research underlying this paper has been supported by grants from the U.S. Air Force Office of Scientific Research through the European Office of Aerospace Research, the Science Research Council and the Royal Society to Professor N. Tinbergen, F. R. S. and myself. It was partly carried out at the Department of Zoology, Oxford. I am grateful to Dr. S. A. Hillyard who by revising an earlier version contributed much to whatever merits this paper has. 
hang mit einer partiellen Schlafaktivierung stehen. Die funktionelle Bedeutung dieses Zusammenhanges und die möglichen physiologischen Mechanismen, die dafür verantwortlich sein könnten, werden diskutiert. Paradoxerweise werden aber Úbersprungsverhalten dann gezeigt, wenn sich Tiere in einem gesteigerten Wachzustand befinden. In diesem Zusammenhang wird das Arousal-Konzept im Lichte der Informationstheorie neu beleuchtet und es wird angenommen, daß der Arousal-Zustand eines Tieres im engen Zusammenhang mit der jeweiligen Informationsverarbeitungsrate im Nervensystem steht. Die Verhältnisse zwischen neuralem und autonomischen Arousal werden diskutiert. Es wird vorgeschlagen, daß sich Überarousal dann einstellt, wenn die Informationsverarbeitungsrate die Kanalkapazität des Systems übersteigt mit einem sich daraus ergebenen. Wirkungsgradverlust. Es wird darauf hingewiesen, daß es Mechanismen gibt, die den Informationsfluß in das Gehirn regeln und angenommen, daß diese innerhalb eines Rücklkopplungssystems funktionieren, welches Arousal reguliert. Diese Regelung benötigt die Aktivierung eines Arousal herabsetzenden Systems, das in den neurologischen Schlafmechanismen besteht. Das Auftreten von Úbersprungsverhalten wird als eine Konsequenz dieser regulatorischen Aktivierung des Schlafsystems angesehen. Die Hypothese wird dann mit den vorhandenen Übersprungsverhaltenstheorien verglichen.

\section{Introduction}

In its normal environment, much of an animal's behaviour appears well adapted and related to the situations it encounters. Occasionally, however, behaviour items may be emitted which seem strikingly unrelated to the environmental context, and in an abnormal environment, such responses sometimes become predominant. This type of behaviour, characterized by its oddity, has attracted the attention of ethologists and has, under the label of "displacement activity," been the subject of a number of studies and theoretical formulations (Zeigler, 1964). In a brief note (Delius, 1967) a different hypothesis was proposed to explain on the basis of certain experimental data the occurrence of this type of behaviour. The purpose of the present paper is to expand and clarify this hypothesis, placing it into a wider context.

Before embarking on this task, however, it is necessary to review briefly some of the concepts and phenomena involved. The term displacement activity is applied to occurrences of particular behaviour paterns in situations where the stimuli normally eliciting them are presumed absent, or at least relatively weak in comparison with those which motivate the behaviour preceding or following. The term is also applied to instances where the occurrence of specific behaviour patterns appears to be functionally irrelevant; that is, when their occurrence appears unadaptive in a given context, from the point of view of the survival of the animal. While these two characterizations may sometimes be in conflict for a particular behavioural event, in general they are complementary. This is not to say that the definition is always satisfactory, because the observer's assessment regarding the presence or absence of causal 
factors could be invalid, or the assumed functions of a given activity could be incorrect. These difficulties are reflected in the ethological literature, where the label of displacement activity, often used in an explanaThis confusion, however, should not lead on to dismiss the phral events. because thorough and knowled neable monographie tre haviour of many species provide relite exper On the basis of careful analyses of the stimulus situations and the relevant responses, authors seem to agree that the situations in which displacement activities are shown can be characterized by one of three over behaviour; frustration, when the animal fails to obtain the terming or consummatory stimulation appropriate to its drive state; or thwarting where the animal is prevented from execting behoviou for which it is motivated (Bastock, Morris and Moynihan, 1953). Exposure to novelty may be added to this list, although possibly this situation can often be may be added to this list, although possibly this situation can often be which displacement activities tend to occur could be characterized as those involving stress.

\section{Theories of Displacement}

To understand the need for a new theory of displacement activities, it is necessary to review critically some of the earlier explanatory formulations. The first was put forward by Tinbergen $(1940,1952)$ and was cast within the framework of the ethological motivation theory current in the forties and early fifties. It postulated that "specific drive energy",
dammed up when consummatory behaviour is blocked by thwarting, condammed up when consummatory behaviour is blocked by thwarting, con-
flict, or frustration, sparks over to another drive system, causing irreflict, or frustration, sparks over to another drive system, causing irreactivities might function to prevent the neurotic behaviour seen in animals which are exposed continuously to these types of stressful situations, a behaviour he interpreted as due to a persistent, excessive, general accumulation of drive energies. The theory has come in for much criticism, some of it probably unwarranted, but it is admittedly doubtful whether Tinbergen's theory has still much explanatory value.

Bindra (1959 b) proposed another theory, based on the observation that situations which give rise to displacement behaviour also increase
general arousal. He hypothesized that this elicits behaviour with hioh habit strength or, in other words, behaviour which is otherwise commonly shown by the species. Although empirical data showing that typical displacement situations do involve increased arousal have accumulated, there is little evidence of an association between high arousal and the 
behaviour shown in displacement outside the displacement situation itself.

Van Iersel and Bol's (1958) model presupposes that drive mechanism are interrelated by a mutual inhibition network which normally prevent hat the most vationel conflict, when two drives are activated to an effective equality mutual inhibition suppresses both conflicting drives to the extent the they cannot inhibit other, even weaker, drives. In other words, througit mutual cancellation of highly activated drives, a weakly activated drive may take control over behaviour due to its disinhibition. Even though the disinhibition hypothesis is supported by a number of experimente studies (Van Iersel and Bol, 1958; Sevenster, 1961; Rowell, 1961), it has the drawback that it deals poorly with the occurrence of displacement behaviour during frustration and thwarting.

To deal with this situation McFarland (1966a) proposed a new theory. When conflict, frustration or thwarting prevent the execution of behavioural responses adequate to the drives activated, there is a mismatch between the stimulus feedback expectation corresponding to the drives, and the feedback actually received. The resulting feedback discrepancy produces a shift of attention and this in turn gives rise to a change of motivation which leads to behaviour other than that originally motivated. In this context, displacement activities could be seen as a by-product of an adaptive change in attention away from the set of stimuli which caused the animal to be faced with a situation it cannot resolve. Although the contention that displacement activities are associated with a shift of attention is supported by a number of ingenious experiments (McFarland, 1965, 1966b), other parts of McFarland's theory remain speculative, particularly the notion that a failure of feedback matching is instrumental in instigating such changes in attention.

Fentress (1968), while accepting the basic validity of the disinhibition hypothesis, proposed that arousal, defined as a relatively unspecifio motivational factor and generated by the displacement situation, is capable of partially controlling behaviour and modulates the effects of the specific drives, which are either those involved in the conflict or other which have become disinhibited. It seems that Fentress, not unlike Bindra (1959 b), assumes that different types of displacement activities may be facilitated, depending on the level of arousal generated by the situation. While his experiments clearly support the view that arousa is involved in displacement activities, the mechanism of its action an its interaction with the disinhibition system are not discussed. 
Finally, an interesting suggestion regarding the function of displacement behaviour was made by Chance (1962). Reviewing a number of behavioural patterns, several of which are typically shown in displacement, he suggested that these activities serve the purpose of diminishing either general arousal or specific drive arousal by a reduction of relevant stimulation through changes in sense organ orientation.

A major criticism of all the preceding theories, except perhaps the last, is that they pay little attention to the fact that quite specific behaviour patterns are consistently and persistently shown as displacement activities by a variety of animal species. One of the explanations which they offer for this consistency is that the patterns shown as displacement activities are behaviours which are also shown frequently by the species in more normal contexts, and are therefore propotent in the animal's repertoire. This implies that in some way the causal mechanisms underlying these patterns ensure a predominance over other types of behaviour. However, there has not been any attempt to support this contention in an empirical way, nor has any detailed suggestion been proposed regarding the response preference mechanism (Bindra, 1959 b; Zeigler, 1964).

Another explanation for this consistency has been that displacement activities are responses to stimuli which are continuously impinging on the organism (van Iersel and Bol, 1958; Rowell, 1961; McFarland, 1965). In other words, it is assumed that in the absence of stronger stimulation the animal will always revert to responding to this background stimulation. This idea has received some support, by showing that the likelihood of displacement activity will increase if the relevant background stimulation is enhanced experimentally. While this suggests that background stimulation might be a significant factor, it does not prove that it is the sole determinant of specific displacement behaviour. These experiments always involved an increase in the stimuli adequate for the typical displacement activities, and no attempts have been made to induce unusual types of displacement activity by subjecting the animal to some quite different kind of stimulation. Thus, the specificity and consistency of the behaviour patterns shown as displacement is not satisfactorily explained by any of the theories.

\section{Displacement and Sleep}

Gulls and other larids show grooming (Tinbergen, 1959; van Iersel and Bol, 1958; Moynihan, 1955; R. G. B. Brown, pers. comm.), staring down (Goethe, 1957) and ground pecking (Tinbergen, 1959) as main 
displacement activities ${ }^{1}$. The results of a systematic exploration of the forebrain of gulls with electrical stimulation suggested a reason for the consistency of these displacement behaviours. It was found that stimulation of various circumscribed brain areas of gulls elicited a behavioural syndrome characterized by the following course of events. Typically, the first effect of the stimulation was to arrest the animal's efforts to break out of the experimental cage, a response which these wild birds showed regularly. Next they changed their posture from one expressing fear, with sto teristic of a and this sometimes wa followed by some cast pects to the flor

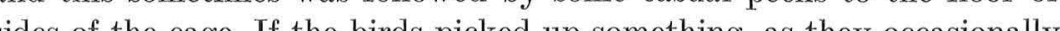
did, they would fling it off with a definite sideward component. Then they would proceed to show a sequence of preening and associated movethey would proct to show a sequence of preening and associated movements, such as head-rubbing, head-scratching, head shaking, tail waggling, shuffling, foot shaking and mandibulating. By this time, the gulls
showed clear signs of drowsiness: yawning, intermittent closing of the eyes, and hunching up with fluffed plumage. Often, they would also squat after seeking one of the cage corners. Most would continue in this state for an extended period, but some actually went to sleep after positioning the head on the back. Considerable external stimulation was necessary to arouse them from this terminal stage, and even then they tended to resume it afterwards (Delius, 1967 ; in prep.).

A similar sequence of behaviour could be obtained from the gulls upon injection of a subanaesthetic intramuscular dose of pentobarbital or an oral dose of tribromoethanol, even though the animals often had difficulties with motor coordination. The unexpected intensity of the pecking was particularly surprising. Anaesthetic dosages of the same drugs consistently elicited preening movements just before the animals lost their balance. Control injections were ineffective and did not modify the persistent escape attempts or tense alarm posture which the animals showed in the test situations. Unpublished observational data on normal animals, both in captivity and in the wild, support the contention that grooming, staring down and yawning are connected with drowsiness and sleep. Prolonged preening bouts almost invariably precede episodes of resting and are typical of instances in which gulls transitorily interrupt their sleep. All the preening shown by active animals could be ascribed either to displacement behavions on lo

1 Other gull behaviours which have been labelled displacement, probably do not qualify as sich
(Cullen, 1966). 
In pigeons and doves, grooming, pecking, and sometimes drowsiness and sleep, are the most common displacement activities in a variety of situations (Fabricius and Jansson, 1963; McFarland, 1965; own observations). Current observations of normal pigeons suggest that there is species. Traradri (1966) reports that grooming, pecking and sleep in this species. Traradri (1966) reports that during interruptions of sleep, pigeons equivalent effect upon pigeons as on the gulls, except that the pecking equivalent effect upon pigeons as on the gulls, except that the pecking component is perhaps more obvious. Operant conditioning workers have
repeatedly noticed the enhancing effect barbiturates have on indiscriminate key pecking (Rutledge and Kelleher, 1965). A similar effect has been noticed with apomorphine, another hypnotic drug (Amsler, 1929; Weissman, 1966). Chloroprotixene, a tranquilizer, elicits both grooming and pecking. Paradoxically, amphetamine can also enhance the occurrence of these patterns, but only when it induces a delayed drowsiness after injection of higher dosages. In the initial active phase, it seems on the contrary, to prevent this type of behaviour.

Electroencephalographic studies suggest that grooming, and possibly pecking as well, are almost invariably associated with low frequency, high voltage waves, which are indistinguishable from those recorded from sleeping pigeons. When grooming occurs in displacement contexts, these slow waves are embedded in low voltage, fast activity records (Delius, in prep.). Brain stimulation of doves has furnished neurological evidence for a common causal mechanism linking grooming and pecking (Harwood and Vowles, 1966).

Grooming, pecking and sleep are the most frequent types of displacement activity among birds other than larids and pigeons. Grooming for example, is the typical displacement activity of the chaffinch (Rowell, 1961); grooming, pecking and sleep that of chickens (Kruijt, 1964; WoodGush and Guiton, 1967); pecking that of the skylark (Delius, 1963) and sleeping that of certain waders (Tinbergen, 1952; Lind 1961).

Grooming, and to a lesser extent sniffing and digging, are reported to be the recurring displacenent patterns of rats (Bindra and spinner, 1958; Grant and Mackintosh, 1963; Bindra and Mendelson, 1963). Grooming is also reported as displacement activity in other rodents (Ewer, $1967 \mathrm{a}$; Fentress, 1968). Bolles (1960) has shown by analyzing the behaviour patterns of normal rats in terms of transition probabilities, that grooming regularly precedes and follows sleeping.

Caspers (1963) has presented evidence that the cortical d.c. potentials, which in the waking rat are characteristically surface negative, show a positive shift when the animal either begins to groom or falls asleep (see also Kawamura and Sawyer, 1966). As in birds, there is evidence 
that tranquilizers and hypnotics facilitate this type of behaviour in rodents. The results with stimulants, however, are conflicting, some authors indicating depression of these activities, others an enhancement (Randrup and Munkvad, 1964, 1965; Fentress, 1968). It could be that the latter findings are due to the same paradoxical effect seen in pigeons, whereby stimulants can sometimes induce drowsiness rather than arousal.

In the cat, sniffing, grooming and lying down bave been reported as displacement (Leyhausen, 1956; Adams, 1921, own observations). Parmesures which elicited sleep also tended to elicit and lying down. The structures which yielded this behaviour were the hippocampus, caudate nucleus, medial thalamus and mammilary body. This can be supplemented with Hess and Meyer's (1956) similar findings for the septum. Parmeggiani also remarks that this association is typical in the normal unstimulated cat, and my own observations strongly support this contention. Ewer's (1967 b) objection that grooming is also frequently shown by cats upon awakening is not crucial, because my own observations indicate that they are still drowsy on such occasions. MacLean (1957) found that both electrical and chemical stimulation of the hippocampus will give rise to a "pleasure syndrome," which inlcudes about neural inactivation is indicated by the fact that it shows the earliest signs of impending cortical EEG synchronization (Jung, 1963). Akert and Anderson (1951) have drawn attention to the behavioural inactivation which follows stimulation of the caudate nucleus, and they specifically noted that grooming is often associated with this inactivation. (See also Buchwald, Hull and Trachtenberg, 1967; Stevens, Kim and MacLean, 1961; Forman and Ward, 1957; Heath and Hodes, 1952). The role of the medial thalamus as a sleep-mediating structure has been demonstrated by Hess (1954) and Monnier, Koller and Hoesli (1965).

Electroencephalographic studies on the cat also support that grooming is associated with "de-arousal." Rowland and Gluck (1960) showe that a conditioning procedure which produced periods of EEG synchronization in sleeping cats also divited grooming in walking ats and Podvoll and Goodman (1967) have directly observed EEG synchronization during grooming.

In the dog, another carnivore, grooming and sleep, along with some autonomic responses are the major displacement reactions to stressing situations (Pavlov, 1955; Schmidt, 1956).

Man also shows responses which can be interpreted as displacement behaviour. The most striking is head-scratching or rubbing of some part of the head, but a number of other irrelevant responses can occur during 
psychological stress. Many of these are apparently grooming behaviours, uch as adjusting of ties in males, hair setting of females, an fingernail biting or fluff picking from clothing (Grant 1968); othe responses are probably not, like the thumb-sucking of children (N. BlurtonJones pers. comm., Eibl-Eibesfeldt, 1967). In more extreme situations, drowsiness and behavioural sleep have repeatedly been reported in man (Oswald, 1962). Sleep is also frequently observed as a response to intense stimulation (Oswald, 1960). This type of reaction may be exaggerated in pathological states like narcolepsy, where even slight stress may elicit sleeping fits (Langworthy and Betz, 1944).

This evidence indicates that in a number of species the behaviour patterns shown as displacement activities, particularly grooming, are also normally associated with inactivity, drowsiness and sleep; indeed, the latter is often itself a displacement response. Whether this can be generalized to other species and to other displacement behaviours remain ncertain, because relevant infor the idea that ind of

The origin of this association is fairly obvious. Much of the animal's behaviour can be assumed to have high priority, in the sense that it cannot be postponed without impairing the animal's or its progeny's sur-
vival: feeding, fighting, courtship etc. These activities typically require vival: feeding, fighting, courtship etc. These activities typically require a high degree of responsiveness to environmental stimuli, with precise
timing and orientation, and often a marked level of motor activity. In brief, animals performing this type of behaviour can be said to be in a state of enhanced wakefulness or arousal.

Other activities, such as grooming and sleeping, are not so dependen on precise timing for functional effectiveness; they have low priority and ean be postponed until the high priority activities have been carried out, without markedly impairing survival. Such behaviour is often characterized by an absence of precise patterning dependent on external stimulation; many appear to be centrally "preprogrammed" motor coordination that only require triggering and involve restricted motor activity. Hence they can be carried out in states of diminished wakefulness. It is therefore reasonable to assume that an organizational pattern which causally linked these activities has been selected for in evolution.

There is uncertainty regarding the causal processes underlying this association. Although there is some contradiction in the relevant studies, it may be that the secondary, long-latency component of the cutaneously evoked potentials at central levels, which seem to be related to the occur- 
grooming, is of a larger amplitude during drowsiness and the early stages of sleep than during wakefulness or deep sleep (King, Nanquet and Magoun, 1957; Favale, Loeb, Manfredi and Sacco, 1965; Belugou an Benoit, 1966; Carli, Kawamura and Pompeiano, 1967). Whether other centres by the sleep system play a role, must remain an open issuc for the time being.

A complementary mechanism may also contribute to the link between sleep and grooming. Roitbak (1960) and Pompeiano (1965) have found that in the cat repetitive stimulation of cutaneous afferents an extremely effective procedure for generating sleep. Such type of stimuation does, of course, arise during grooming and it is conceivable that if grooming is triggered perhaps by external stimulation, it could throug this mechanism tend to be followed by sleep. The implication that the performance of certain types of activities is conducive to the induction of sleep or at least relaxation is not a new idea; in man, for example, the performance of a repetitive behaviour pattern (Oswald, 1962), lyin down (postural facilitation, Lind, 1959) or closing the eyes (eut-off, Chance, 1962) is claimed to have such an effect. Here then, the activatio of grooming and perhaps some oller behaviour patterns would be the primary response, and sleep or drowsiness the secondary effect following it.

The nature of the connection of some of the other behaviour pattern with sleep is less obvious, particularly the staring down and pecking of birds. Possibly it follows an efferent suppression of the peripheral visua fields by the sleep syst an. Ihis then enhances behaviour controlled by evel vision (so callod tumi vision), lating surroundings.

\section{Arousal Reinterpreted}

In the previous section, I have presented evidence that behaviour shown as displacement activity is also behaviour which is normally associated with sleep. The simplest explanation of this phenomenon would be that the displacement situations are effective in directly elicitin sleep, or at least drowsiness and inactivity. This economical interpretation, however, has difficulties. Displacement activities occur in behaviioural contexts which are characterized on the contrary by a high degree of wakefulness, activity, responsiveness, or in other words by high level of arousal. Evidence for this view comes from both behavioural observations and physiological measurements. All the behaviou seen in displacement selves, is indicative of marked arousal, as for example fighting, fleeing, 
courtship, exploration etc. Conflict, thwarting, frustration, novelty, have all been shown to be associated with high levels of arousal, as indexed by various physiological measures (Bindra, 1959a; Berlyne, 1960; Johnson, 1962). In pigeons, displacement activities always occur in contexts of marked electroencephalographic arousal (Delius, in prep.). It is, of course, on this evidence that Bindra (1959 b) proposed the arousal hypothesis of displacement activities.

Before proceeding to explain this apparent paradox, it is necessary to examine the concept of arousal more closely. A universally accepted definition of arousal does not seem to exist, but there is tacit agreement that it is a hypothetical physiological variable which correlates with overall behavioural responsiveness and activity, not necessarily always in terms of overt physical behaviour, but also as covert nervous system activity. Often arousal has been considered coextensive with some conception of general drive, probably because it seems to affect a wide range of behaviour. A number of physiological, rather than behavioural, measures have been used to assess the arousal state of animals including man, perhaps reflecting the relative ease with which they can be quantified. Among the physiological measures, the electroencephalogram seems to have gained prevalence, because it reflects the activity of the ascending reticular activating system which regulates behavioural wakefulness and responsiveness (Lindsley, 1960). Strong criticisms have been raised on a variety of grounds against the use of arousal as an explanatory construct (Lacey, 1962; Hinde, 1966), but it is difficult to dismiss the everyday experience that the level of wakefulness is important in determining, or at least modulating, the more specifically motivated behaviour.

The generally accepted notion that the central function of the nervous system is an information-processing system (Quastler, 1955) provides a framework within which the arousal concept may be more meaningfully and precisely specified. The contention is that arousal is equivalent, or at least related, to the overall rate of information processing in the nervous system (Welford, 1962), measured perhaps in terms of number of elementary logical decisions per unit time ${ }^{2}$. While operationally this definition is not ideal, ordinal estimates of information processing rates should at least be possible under controlled environmental conditions.

Some successful efforts have been made to obtain empirical correlations between this type of measure and more conventional ones of arousal,

2 Whether elementary logical decisions are the most adequate units for quantifying the processing of information in the nervous system must be left open in view of our restricted knowledge about the operating modes of neuronal nets. Single unit activity, even when integrated, is almost certainly not a good index of information processing (Evarts, 1964). 
by exposing subjects to various degrees of informational influx or requiring them to process given information to various degrees (Weinberger and Lindsley, 1964; Berlyne and McDonnell,1965; Kahneman and Beatty,
1966; Bradshaw, 1967). The classical states of electroencephalographic arousal in the wakefulness-sleep continuum fall in place with this conception, particularly if one considers rapid-eye-movement sleep where an
aroused electroencephalogram correlates with dreaming, an acitivity clearly involving information processing. Generally, however, it must be taken into account that the electroencephalogram only reflects cortical activity, while doubtlessly subcortical structures are equally involved in information processing.

Some of the aspects of the conventional concept of arousal are less easy to accommodate with the reinterpretation given above, notably the autonomic symptoms. To be effective, much of an organisms information processing depends on behavioural activities which require a varying distribution of metabolic energy. The autonomic responses are mainly adapted to achieve this. Generally, high rates of information processing are most likely to entail a high rate of responding. The organism appears to anticipate the energy requirements partly on the basis of the overall rate of information processing, as well as on more specific information. This explains the overall correlation between neural and autonomic arousal, and their unreliability in specific instances, since many processes involving a high rate of information handling are associated with low levels of motor activity, for example, dreaming, and inversely, high levels of motor activity may involve little processing as in the case of reflexive responses.

If arousal is interpreted in this way, the concept of limited channe capacity is relevant. This property of information channels entails that any given information-processing system has a maximum capacity for effective handling or processing of information; if the information input rate is above this limit, then the effective processing diminishes (Zemanek, 1959, Miller, 1964). ${ }^{3}$ The limited channel capacity of the nervous system may be due to a multitude of factors: slow responding; low transmitting rates; noise interference liability; low reliability of neural elements and connections; slowness, dearth of memory elements; inertia of response organs, etc. Whatever the reason for its existence, there is ample empirical evidence that a limited information processing capacity is a character-
istic parameter of the brain, as it is of any other information channel

Strictly speaking, this has only been formally proven for information transprocessing system 
(Augenstein and Quastler, 1967). Its precise quantification, however, offers difficulties because of the multifarious operating modes the nervous system can assume, each involving different and mostly unknown inforare as yet possible as to whether the informational bottlenecks limiting the capacity in the various situations are at perceptual, motivational or motor coordination levels (Quastler, 1956).

At this point it may be as well to introduce considerations which complicate the issue, as they imply that channel capacity is not an though mainly an information-processing device, must, as all biological tissues do, fulfill metabolic functions. There is evidence that the two types of activities are at least partially incompatible (Moruzzi, 1966). This means that the channel capacity of the nervous system depends on whether it is predominantly engaged in metabolic recovery or in information processing. While the operating modes are switched by an automatic wake-sleep cycle (Aschoff, 1965), they can be overridden when certain stimuli impinge on the animal, causing the recovery function to be postponed and the channel capacity to be expanded. Behaviourally, this is the orienting or alerting response (Sokolov, 1960). Stimuli therefore may have a dual effect, opening up channel capacity and causing an increase in the processing rate.

Since the evolutionary development of advantageous additional channel capacity, in the form of a larger nervous system, is associated with counteracting selective pressures, deriving from the disadvantages of such larger brains (Rensch, 1954), one must assume that the channel capacity of any one animal species represents a compromise. It follows then that information-processing capacity of individuals will often be challenged in the course of their life, even in their normal environment. It also follows that mechanisms preventing such information overload, but do not involve brain growth, will be selected for.

Behavioural evidence for the existence of such mechanisms comes from studies on selective attention. They show that while excessive information intake by human subjects impairs their performance, they often are capable of suppressing some of the impinging information (Broadbent, 1965), mostly at an early stage in the processing system, but sometimes also after it has already undergone some evaluation (Treisman, 1969). Animals in discrimination learning situations apparently respond in a similar way, selectively disregarding information which is potentially available to them when solving complex tasks (Sutherland, 1964; Mackintosh, 1966). 
Physiological evidence indicates that animals and man have mechanisms which can control the influx of information. In virtually all sensory systems which have been studied with this in view, it has been found that from the very earliest input stages onwards there are efferent neural pathways which are capable of inhibiting their transmitting properties (Horn, 1965). Some of the control may involve actual behavioural responses such as pupil contractions and pinna reflexes. The central origin of the centrifugal pathways is varied, suggesting a highly complex control of the sensory information influx. Behavioural evidence indicates that at times the organism attends to only one of the sensory qualities and at other times sensory inputs are selected depending on their relevance to ongoing behaviour or according to their spatial origin (Berlyne, 1968). Other patterns of attention switching may again be based on an automatic cycling between inputs (Scheibel and Scheibel, 1965) or on habituation-dishabituation processes (Horn, 1967). Whatever the detailed mechanisms however, their can be no doubt that the nervous system exerts a control over its information intake so as to operate within its optimal capacity.

We have so far addressed the situation in which the organism faces an excess of information, but obviously it must often encounter situations where it is informationally undertaxed. The occurrence of such episodes is unadaptive as the animal is wasting information acquisition potential. There seem to be various ways in which this is avoided, one is the retrieval and handling of internal information drawn from memory stores, a process as yet not detectable other than by introspection in humans (thinking, Reitman, 1965); another is the seeking of information through behavioural activity (exploration, Fowler, 1965; Haywood and Wachs, 1967). The latter provides useful information for the animal's survival, enabling it to know and predict the environment with more reliability. Processing of stored information may possibly bring that information into a less redundant, higher order form.

In other words, if arousal is equivalent to the information processing rate, the information input regulation I have discussed closely matches the concept of "arousal homeostasis" proposed by various authors; that is, that animal and man strive to maintain a certain level of arousal (Hebb, 1949; Schlosberg, 1954; Berlyne, 1960; Hutt, Hutt, Lee and Ounsted, 1964; Schultz, 1965). The focusing on information, however, provides a powerful logical argument for the existence of such an homeostatic process, because it makes clear a biological need for it. The status of arousal thereby becomes similar to that of some classical drives, hunger and thirst, perhaps with the interesting peculiarity that it has a bidirectional drive characteristic. Both reduction of excess and deficit of information are sought by the organism, depending on environmental conditions. 


\section{The De-arousal Hypothesis}

At this point it is possible to return to displacement activities. As we have seen, the situations in which displacement activities occur: conflict, frustration, thwarting and novelty, are associated with signs of arousal in the conventional sense; in other words, the animals show signs of enhanced responsiveness, marked activity and electroencephalographic as well as autonomic signs of increased arousal. Paradoxically, however, we have also seen that some of the behaviour patterns shown in displacement are associated, by various criteria, with the incipient activation of sleep. In the context of the foregoing this contrast is highly suggestive of a regulatory process, where the activation of sleep system counteracts an increase in arousal.

The displacement situations can be assumed to provide the animal with more information and to demand from it more information processing than other situations. In conflict, it is exposed to two contradictory assemblies of information, between which it has to choose. In the frustration and thwarting situation, an established sequence of behaviour leads to failure, and presumably the animal engages in finding alternative solutions, a process which must require intense information sampling and processing. In the case of exposure to novel stimuli, the increased information influx is obvious. More precise data on this point are needed, but as yet are difficult to come by, because estimates of information processing rates presume a reasonably good knowledge of the processing modes used by the nervous system. Accepting that the displacement situations involve relatively high rates of information handling, it seems likely that they could often entail an overloading of the channel capacity with a consequent deleterious effect on the organisms efficiency. To counteract overloading in such situations I suggest that a reduction in the processing rate is achieved by a concomitant activation of an arousal inhibiting mechanism, the sleep system, which has the property of reducing the overall information influx into the animal. Displacement activities are the epiphenomenal consequence of this feedback activation of sleep.

It is not possible to specify with any certainty at this stage the detailed neural organization of this regulating mechanism. I suggest that the level of arousal (i.e. the information processing rate) is monitored either via a polysensory system, like the reticular formation, or through detection of an electrical concomitant of a high level of processing, such as d.c. potential changes, or perhaps by measuring the level of some metabolic consequential correlate of arousal. When the measure exceeds a certain level in relation to the channel capacity, it leads to the activation of the sleep system or a related deactivating mechanism. 
There is empirical evidence that strong activation of the reticular forma tion leads to a rebound activation of the sleep system which in turn inhibits the reticular fomation (Dell, Hugelin and Bonvallet, 1961 Parmeggiani, 1968). Whether this is a purely neural process or, whether Miller and Goodich 1067) play a

The activation of the sleep system, either directly or through the inhibition of the reticular activating system, affects the afference of sensory information through the centrifugal control mechanisms of sensory pathways (Koella, 1966). I contend that this leads to a reduction of the attention span, that is to an overall reduction of the information inflow and hence of the information processing rate (i.e. arousal), throug ensory

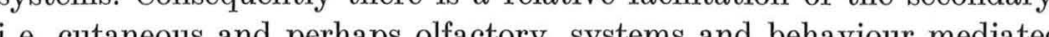

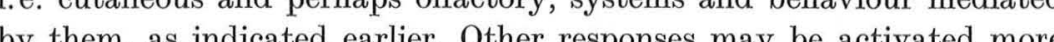
directly by the dear of the activities so indueed may in turn be conducive to a rodution of arousal either by cutting down sensory input or by generating repetitive stimulation facilitating the induction of sleep and thereby rinforcing the original process (Mason, 1967).

It is not clear why displacement activities do not always include the complete gamut of sleep-related behaviours (Ewer, $1967 \mathrm{~b}$ ). Two factors

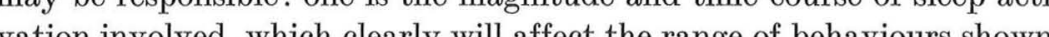
high dose of berites gives the anima ne or toro grom

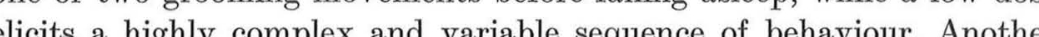
possibility arises from the fact that the sleep system cannot be viewed s a unitary center but rather as complex network with more or differentiated subdivisions, as demonstrated, for example, by the existence of soparte though related mechenisms for slow and fast sloep (Jouvet, 1967). Which of these subdivisions are involved in displacement, and how their activation affects the behaviour of the waking animal, must remain open.

Any of this behaviour may of course be further modified by incidental adequate external and internal stimulation. For example, displacement grooming might be facilitated by suitable cutaneous stimulation or by pre-existing partial activation of the sleep system, while displacemen equence of this is that a clear-cut distinction between normal and dis- 
placement occurrences of given behaviour patterns is not possible, in agreement with most observational data; this may have to do with the

Although it is proposed that displacement activities are the reflection of a de-arousal process, they do occur in a context of high arousal, so one may expect that some of the behaviours shown in these situaand Guiton (1967), for example, found that chickens would often react with frantic escape attempts to a thwarting procedure which reculacty also yielded displacement orooming and sleep. Similar escape regularly also yielded displacement grooming and sleep. Similar escape behaviour tivating system in gulls (Delius, in prep.), apparently as a direct effect of high arousal. Pigeons show similar escape behaviour in novelty situations, and EEG recordings support the view that this reflects a state of extreme arousal (own observations). Similarly, if the animal is informationally challenged when it is operating below its maximum channel capacity, it may be assumed that the system's first response will be to increase its attention span. Some of the alerting or orienting patterns seen in stress situations may therefore reflect this process (Berlyne, 1967). As we have argued, there are reasons for assuming an overall correlation between central and autonomic arousal and so we may expect that displacement situation will also give rise to autonomic responses. Schmidt (1956) provides good examples of this in dogs exposed to frustrative situations, with panting, salivation, defaecation and urination occurring along with displacement grooming and sleep. Similar behaviour appears to be recorded in the open field test for emotionality in rats and mice (C. van Toller, pers. com.).

Finally one would expect the proposed homeostatic process to fail on occasions, resulting in over-arousal to the extent that the organism becomes behaviourally ineffective. This is reflected in the so-called freezing state many animals fall into when facing extreme stressful situations re frezing rabbits (own obervations) or lions kill apparently paralyzed to have mans or zebras (H.Krunk, pers. com.). Liven so, many species seem haviour: Comparing the de-arousal hypothesis with other theories of displaceCont, its main virtue is that it explains the specificity and consistency ment, its main virtue is that it explains the specificity and consistency of the behaviour shown in displacement situations and moreover, it with the fact that displacement occurs in contexts of high arousal (Bindra, 1956 b) and that the level of arousal modulates irrelevant be- 
haviour (Fentress, 1968). It is concordant with the disinhibition hypothesis (van Iersel and Bol, 1953), in admitting that peripheral stimulation can play a role in determining the displacement behaviour, but has no difficulty in explaining its occurrence in frustration and thwarting situations. It also accepts that shifts of attention (McFarland, 1966a) are involved in bringing about displacement activities. The functions of displacement activities in the context of the de-arousal hypothesis are consistent with those suggested by Tinbergen (1952) and Chance (1962): avoidance of disruption of neural processes through a reduction of arousal.

When assessing the value of the various theories, consideration must be given to the possibility that the displacement phenomena are heterogeneous. It may be, for example, that the disinhibition hypothesis is a satisfactory explanation of the displacement fanning of sticklebacks (Sevenster, 1967, but see Wilz, 1967), but that the de-arousal hypothesis gives a more adequate account of the causal processes underlying displacement grooming in gulls. The fact that grooming is the dominant displacement pattern in a wide range of species from insects to man, however, suggests that at least this type of displacement should be explainable in terms of a single universal hypothesis.

To close, an alternative line of explanation, perhaps related to the de-arousal hypothesis, should be mentioned. As indicated earlier, the situations in which displacement activities occur can be characterized as stressful. Adrenocorticotrophic hormone injected into the brain ventricles of cats elicits yawning and stretching behaviour (Gessa, Pisano, Vargiu, Crabai and Ferrari, 1967). These responses are sometimes seen in conjunction with the more common displacement activities of the cat. ACTH secretion is known to follow the induction of psychological stress and takes place in the adenohypophysis, but probably also at some unidentified ventricular secretory organ (Frankel, Graber and Nalbandov, 1967). Among the target organs of ACTH is the hippocampus (aus der Mühlen and Ockenfels, 1968), which is involved in deactivation as mentioned. earlier and seems in turn to control ACTH secretion (Mason, Nauta, Brady, Robinson and Sacher, 1961/62). Possibly, displacement acitivities are just one component of the general adaptation syndrome (Selye,1959), the organism's response to stress.

\section{References}

Adams, D. K.: Experimental studies of adaptive behaviour in cats. Comp. Psychol. Monogr. 6, 1-69 (1921).

Akert, K., Andersson, B.: Experimenteller Beitrag zur Physiologie des Nucleus caudatus. Acta physiol. scand. 22, 281—297 (1951). 
Albe-Fessard, D., Massion, J., Hall, R., Rosenblith, W.: Modifications au cours de la veille et du sommeil des valeurs moyennes de réponses nerveuses centrales
induites par des stimulations somtiques chez le chat libre. C. R. Acad. Sci. induites par des stimulations somtiques chez le chat libre. C. R. Acad. Sci
(Paris) 2588, 3553-356 (1964).

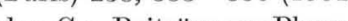

Amsler, C.: Beiträge zur Pharmakologie
exp. Path. Pharmak. $97,1-14$ (1923). Aschoff, J.: Circadian rhythms in man. Science 148, 1427-1432 (1965).

Augenstein, L., Quastler, H.: Information processing and decision making in man. Brain Res. 6, 587-605 (1967).

Bastock, M., Morris, D., Moynihan, M.: Some comments on conflict and thwarting

building in the laying and incubation periods. Behaviour 21, 155-176 (1963).

Belugou, J. L., Benoit, O.: Activité unitarie spontanée des noyaux de relais somes-
thétiques pendant la veille et le sommeil. J. Physiol. (Paris) 58, 461-462 (1966). thétiques pendant la veille et le sommeil. J. Physiol. (Paris) 58, 461-462 (1966).
Berlyne, D. E.: Conflict, arousal and curiosity. New York-Toronto-London: McGraw Berlyne, D. E.: Conflict, arousal and curiosity. New York-Toronto-London: MeGray
Hill 1960.

Arousal and reinforeement. In: D. Levine (ed.) Neb
vation. Lincoln: University of Nebraska Press 1967.

The development of the concept of attention in psytloges and T. Mulholland (ed.), Attention as a the

FEG desyncenisation. of stimulus complexity and incongruity on duration of Bindra, D.: Motivation. New York: Ronald Press 1959a.

- An interpretation of the "displacement phenomenon". Brit. J. Psychol. 50,

- Mendelson, J.: Training, drive level, and drug effects. A temporal analysis of (1963)

- Spinner, N.: Response to different degrees of novelty: the incidence of varions activities. J. exp. Anal. Behav. 1, 34I

Bolles, R. C.: Grooming behaviour L he rat. J. comp. physiol. Psychol. 53, 306-

Bradshaw, J.: Pupil size as a measure
Nature (Lond.) 216, $515-516$ (1967).

Broadbent, D. E.: Information processing in the nervous system. Science 150, $457-$

462 (1965).
Buchwald, N. .., Hull, C. D., Trachtenberg, M. C.: Concomitant behavioural and neural inhibition and disinhibition in response to subcortial stimulation Exp. Carli, G., Kawamura, H., Pompeiano, O.: Transmission of somatosensory volleys through ascending spinal hind limb pathways during sleep and waketiness.

Caspers, H.: Relations of steady potential shifts in the cortex to the wakefulness
sleep spectrum In: M. A. B. Brazier (ed.), Brain function. Berto to University of California Press 1963.

Chance, M. R. A.: An interpretation of some agonistie postures; the role of "cut-off" 
Cullen, J. M.: Ritualization of animal activities in relation to phylogeny, speciation and ecology. Phil. Trans. B 251, 363-374 (1966).
Delins, J. D.: Das Verhalten der Feldlerche. Z Tierpsychol. 20, 297-348 Delius,

- Displacement activities and arousal. Nature (Lond.) 214, 1259-1260 (1967). - Maintenance behaviour in gulls elicited by brain stimulation. (In prep.).

G. E. W. Wolstenholme and M. O'Connor (eds.), The nature of sleep. London Churchill 1961.

Eibl-Eibesfeldt, I.: Grundriß der vergleichenden Verhaltensforschung. Munich:

Evarts, E. V.: Temporal pattern of discharge of pyramidal tract neurons during sleep and waking in the monkey. J. Neurophysiol. $27,152-171$ (1964).
Ewer, R. F.: The behaviour of the african giant rat (Cricetomys gambianus Waterhouse). Z. Tierpsychol. 24, 6-79 (1967 a).
hour

Displacement and de-arousal. Nature (Lond.) 216, 686 (1967 b).

Fabricius, E., Jansson, A. M. - Laboratory observations on the reproductive behaviour of the pigeon (Columba livia) during the pre-ineubation phase of the breeding cycle. Anim. Behav. 11, 534-547 (1963).

avale, E., Loeb, C., Manfredi, M., Sacco, G.: Somatic afferent transmission and cortical responsiveness during natural sleep and arousal in the cat. Electro-

entress, J. C.: Interrupted ongoing behaviour in two species of vole (Microtus
agrestis and Clethrionomys britannicus). Anim a in cats in chronic experiments. J. Neurophysiol. 20, 230-244 (1957). Fowler, H.: Curiosity and exploratory behaviour. New York: MacMillan 1965. Frankel, A. I., Graber, J. W. Nalbandov, A. V.: Adrenal function in cockerels. Endocrinology 80, 1013-1019 (1967). Gessa, G. L., Pisano, M., Vargiu, L., Crabai, F., Ferrari, W.: Stretching and yawn
ing movements after intercerebral injection of ACTH. Rev. canad. Biol. 26 (Go

Goethe, F.: Das Herabstarren,
haviour 11, $309-317(1957)$.

(1) news. Brit. J. Med. Psychol. 41, 177 of nouves

news. Brit. J. Med. Mychl. 41, $77-186$ (

(n) ratory rodents. Behaviour 21, 246-259 (1963).

Harwood, D., Vowles, D. M.: Forebrain stimulation and feeding behaviour in the
ring dove (Streptoplia ring dowe
(1966).

Haywood, H. C., Wachs, T. D. Effects of arousing stition upon novelty preference in rats. Brit. J. Psychol. 58, $77-84$ (1967).

Heath, R. G., Hodes, R.: Induction of sleep by stimulation of the caudate nucleus Hebb, D. O.: The or und 

Hess, W. R.: The diencephalon: autonomic and extrapyramidal functions. New
York: Grune \& Stratton 1954. Meyer, A. E.: Triebhafte Fellreinigung der Katze als Symptom diencepha-
ler Reizung. Helv, physiol. pharmacol. Acta 14, 397-410 (1956). Hinde, R. A.: Animal behaviour. London: MeGraw-Hill 1966.

Horn, G.: Physiological and psychological aspects of selective perception. In:
D. S. Lehrman, R. A. Hinde and E. Shaw (eds.), Advances in the study of behaviour. New York and London: Academic Press 1965.

(1967). Hutt, C., Hutt, S. J., Lee, D., Ounsted, C.: Arousal and childhood autism. Nature (Lond.) 204, 908-909 (1964). lersel, J. J. A. van, Bol, A. C.: Preening of two
ment activities. Behaviour 13, $1-88$ (1958).

Johnson, H. J.: Decision-making, conflict and physiological arousal. Illinois, Ph.D. thesis (1962).

Jouvet, M.: Neurophysiology of the states of sleep. Physiol. Rev. 47, 117-177

ung, R.: Der Schlaf. In: M. Monnier (ed.), Physiologie und Pathophysiologie des S. Stuttgart: Hippokrates 196

$1585(1966)$. and paradoxical sleep. Amer. J. Physiol. 207, 1379-1386 (1966).

ing, E. E., Naquet, R., Magoun, H. W.: Alterations in somatic afferent trans-

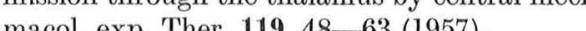

1966

ruijt, J.: Ontogeny of social behaviour in Burmese Red Jungle Fowl (Gallus gallus spadiceus). Behaviour, Suppl. 12, 1-162 (1964).
gents

cey, J. I.: Somatic response patterning and stress: some revisions of activation theory. In: M. A. Appleby and R. Turnbull (eds.), Psychological stress: Some

Langworthy, O. R., Betz, B. J.: Narcolepsy as a type of response to emotional cyhausen, P.: Verhaltensstudien bei Katzen. Z. Tierpsychol., Suppl. 2 (1956). Lind, H.: The activation of an instinct caused by a "transitional action". Behaviou 14, $123-135$ (1959).

Studies on the behaviour of the Black-tailed Godwit [Limosa limosa (L.)]

Lindsley, D. B.: Attention, consciousness, sleep and wakefulness. In: J. Field, H. W. Magoun and V. E. Hall (eds.), Handbook of physiology, sect. 1, vol. 3.
Washington: Amerioan Psychological Society 1959 . Tackintosh, N. J.: Selective attention in animal learning. Psychol. Bull. 64, 124150 (1966).

MacLean, P. D.: Chemical and electrical stimulation of the hippocampus in un restrained animals. Arch. Neurol. Psychiat. (Chic.) 78, 128-142 (1957). 
Mason, J. W., Nauta, W. J. H., Brady, J. V., Robinson, J. A., Sachar, E. J.: The role of limbic system structures in the regulation of ACTH secretion. Acto

neuron, W. A.: Motivational aspects of social responsiveness in young chimpanzees.
In: H. W. Sterenson (ed.) Farly behaviour: comparntive and derelopmental approaches. New York: Wiley 1967. cFarland, D. J.: Hunger, thirst and

nd displacement pecking in the Barbary dove. On the causal and functional significance of displacement activities. Z. Tierpsychol. 23, 217-235 (1966a).

- The role of attention in the disinhibition of displacement activity. Quart. J.

Miller, J. G.: Adjusting to overloads of information. Res. Publ. Ass, nerv, ment. Dis. 42, $87-100$ (1964).

Monnier, M., Koller, T., Hoesli, L.: Humoral mechanism in experimental sleep. In: M. Jouvet (ed.), Aspects anatomo-fonctionnels de la physio
Paris: Centre Nationale des Recherches Scientifiques 1965.

Moruzzi, G.: The functional significence of sleep with particular regard to the brain mechanisms underlying consciousness. In: J. C. Eecles (ed.), Brain and Berlin-Heidelberg-New York: Springer 1966.

Moynihan, M.: Some aspects of reproductive behaviour in the Black-headed Gull (1955)

Uuehlen, K. aus der, Ockenfels, H.: Morphologische Veränderungen im Diencephalon und Telencephalon nach Störungen des Regellkeises Adenohypophyse-
Nebennierenrinde. Z Z Zellforsch. 85 . 124 d44 (1968)

Oswald, I.: Falling asleep open-eyed during intense stimulation. Electroenceph. in. Neurophysiol. 12, 544-551 (1960).

Sleeping and waking. Amsterdam and New York: Elsevier 1962.

Pappenheimer, J. R., Miller, T. B., Goodrich, C. A.: Sleep-promoting effects of cere-
brospinal fluid from sleep-deprived goats. Proc. nat. Acad. Sci. (Wash.) 58 brospinal fluid
$513-517(1967)$

Parmeggiani, P. L.: Sleep behaviour elicited by electrical stimulation of cortical and subcortical structures in the cat. Helv. physiol. pharmacol. Acta 20, Telencephalo-diencephalic aspects of sleep mechanisms. Brain Res. 7, 350-359 (1968).

Pavlov, I. P.: Selected works. Moscow: Foreign Languages Publishing House 1955 Sci, L. M.., Goodman, S. J.: Averaged neural electrical activity and arouse

ompeiano, O.: Ascending and descending influences of somatic afferent volleys in
unrestrained cats: supraspinal inhibitory control of spinal reflexes during natural and reflexy-induced sleep. In: M. Jouvet (ed.), Aspects anatomo-fonctionnel dignes 1965 . (1)

Press 1955 Studies of human channel capacity. In: C. Cherry (ed.), Information theory,
p.361-371. London: Butterworths 1956. 
Randrup, A., Munkvad, I.: On the relation of tryptaminic and serotonergic mechanisms to amphetamine-induced abnormal behaviour. Acta pharmacol. (Kbh.)
$21,272-282(1964)$ pharmacologia (Berl.) 7, amp-416 (1965). Reitman, W. R.: Cognition and thought. New York and London: Wiley 1965. Rensch, B. : Neuere Probleme der Abstammungslehre. Stuttgart: Enke 1954. Roitbak, A. I.: Electrical phenomena in the eerbral cortex during the extinction
of orientation and conditioned reflexes. Moscow Colloquium. Electroenceph of orientation and conditioned reflexes. Moscow Colloquium. Electroenceph.

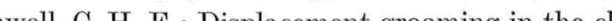

in the chaffinch. Anim. Behav. 9, 38-63 (1961).

Rowland, V., Gluck, H.: Electroencephalographic arousal and its inhibition as studied by auditory conditioning. In: J. Wortis (ed.), R
biological psychiatry. New York: Grune \& Stratton 1960.

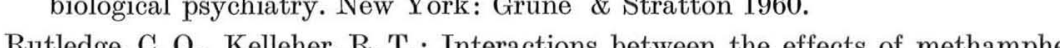
tatledge, C. O., Kelleter, R. T.: Interactions between the effects of methamphe cologia (Berl) 7, 400-408 (1965).

Scheibel, M. E., and A. B.: Periodic sensory non-responsiveness in reticular neurons.
Arch. ital. Biol. 103, 300-316 (1965). Schlosberg, H.: Three dimensions of emotion. Psychol. Rev. 61, 81-88 (1954). Schmidt, H. D.: Das Verhalten von Haushunden in Konfliktsituationen. Z. Psy-

Schultz, D. P.: Sensory restriction. New York and London: Academic Press 1965. Selye, H.: Perspectives in stress research. Perspect. Biol. Med. 2, 403-416

evenster, P.: A causal analysis of a displacement activity (Fanning in Gasterouppl. 9, 1-170 (1961).

sokolov, E. N.: Neuronal models and the orienting reflex, In: M. A. B. Brazier (ed.), The central nervous system and behaviour. New York: Josiah Macy Jr.

Stevens, J. R., Kim, C., MacLean, P. D.: Stimulation of caudate nucleus. Arch. Neu-

1. N. Visual diserimination in animals. Brit. med. Bull. 20, 54-59

Tinbergen, N.: Die Übersprungsbewegung. Z. Tierpsychol. 4, 1-10 (1940).

- Derived activities: their causation, biological significance, origin and emancipation during evolution. Quart. Rev. Biol. 27, 1-32 (1952).

- Comparative studies of the behaviour of gulls (Laridae): a progress report. Be

Traradri, V.: Sleep in the pigeon. Arch. ital. Biol. 104, 516-521 (1966).

reisman, A. M.: Strategies and models of selective attention. Psychol. Rev. 76

Weinberger, N. M., Lindsley, D. B.: Behavioural and electroencephalographic aroueissman, A.: Apomorphine elicitation of key pecking in a pigeon. Arch. int.
Pharmacodyn. 160, 330-332 (1966). 
Welford, A. T.: Arousal, channel-capacity and decision. Nature (Lond.) 194, 365(1) hwarting in the domestic fowl

Wilz, K.J. The organisetion of courtship behaviour in sticklebacks. Ph. D. Thesis, Wilz, K. J.: The
Oxford 1967 .

Zeigler, H. P.: Displacement activity and motivation theory. A case study in the

Zemanek, H.: Elementare Informationstheorie. Vienna-Munich: Oldenbourg 1959.

Juan D. Delius

Department of Psychology

Durham/England 